\title{
Exploratory Study of the Idling Driving Effect on Gas Emission Levels in a Traffic Jam Environment: Case Study of Jakarta Metropolitan Traffic on Gasoline Passenger Cars
}

\author{
Abdi Pratama*, Akihiro Tokai, Hoa Thi Nguyen, Kojima Naoya \\ Division of Sustainable Energy and Environmental Engineering, Graduate School of Engineering, Osaka University \\ Osaka, Japan \\ *Corresponding author's email: totemojapan [AT] yahoo.com
}

\begin{abstract}
In this paper, we measured the potential avoidable emissions in Jakarta city, one of the busiest cities in the world for traffic. We analyzed its impact on the total emissions from passenger gasoline cars. We recorded each designated road to estimate the idling time during travelling and calculated the avoidable emissions of $\mathrm{CO}, \mathrm{NO}$, and $\mathrm{HC}$ gas from vehicles. We determined that more than $46.0 \%$ of the recorded lost travel distance occurred with an average speed $<5 \mathrm{~km} / \mathrm{h}$. Expanding idling driving to $<10 \mathrm{~km}$ added a $+10.0 \%$ contribution to the avoidable emissions. The $46.0 \%$ portions contribute to the current emission levels. However, because of the limitations of the work in this field, the last portion is often neglected in past work. In 2040, CO, NO, and HC showed similar tendencies with an emission difference of more than $46.0 \%$ or 481.79 thousand tons for CO, 2,275 thousand tons for NO, and 20,472 thousand tons for HC. Idle driving contributes to the emissions in traffic jam conditions in Jakarta city. The increase of avoidable emissions is strongly supported by the high growth rate of vehicles by more than $9.0 \%$ every year, which is larger when compared to the annual road growth that only averages $0.01 \%$. We have concluded that avoidable emissions during traffic jams needs to be urgently solved. Eliminating emissions during idling conditions using a technological approach or by conducting idle driving education are two potential ways to reduce avoidable emissions during traffic jams.
\end{abstract}

Keywords_ Jakarta, traffic jam, avoidable emission.

\section{INTRODUCTION}

Jakarta, the target city in this paper, is one of the busiest capitals in the world. The traffic condition is also terrible. One of the traffic contributions comes from the rapid growth of vehicles. Annually, the increase of vehicles registered is more than $10 \%$, in which passenger cars have contributed more than $9 \%$ over the last five years as described in Table 1 . Motorcycles hold the highest percentage out of the documented vehicle composition, taking up more than $74 \%$ of the total vehicles (Badan Pusat Statistik Jakarta, 2015).

Moreover, the traffic condition has worsened due to the slow road construction growth that is based on the promptness of the Indonesian transportation authority over the last four years (2010-2014). While the average annual road construction growth has only been around $0.01 \%$, this is less than 900 times the growth of vehicle demand (Jakarta, 2014). Consequently, the traffic density has become higher and this seems to accelerate the frequency of traffic jams. This high traffic density will also cause unnecessary air pollution from the exhaust pipes and fuel consumption that occurs.

In this paper, we have studied the effectiveness of idling control related to the traffic density condition in Jakarta city in order to investigate avoidable emissions during traffic jams. Regarding this topic, we have investigated the effectiveness of introducing a Low Cost Green Car (Pratama and Tokai 2018) and scrappage incentive program for old cars (Pratama \& Tokai, 2018). In this paper, we tackled issues related to the idling driving condition. Idling generates a certain amount of emissions (Gaines, Rask \& Keller, 2012). As idling is relevant to road structure, there are a few idling controls that are effective for emission control. However, even after a government emission regulation was issued and due to the technological development of environmentally-friendly cars, peoples' driving behavior remains the target of automobile emission control.

During traffic jam conditions, vehicles are often in a state of idling. However, there will still be continuing emissions due to the engine combustion. As for the environmental impact, not only are there gas emissions (CO, NO, HC), but fuel will also be wasted. These conditions should be reduced or avoided entirely if possible. In previous work, Shancita et al. (2014) discussed the impact of idle driving on emissions (CO, NO, HC) and fuel consumption, related to gasoline cars as 
well as diesel cars.

However, research working on clarifying of the effectiveness of controlling the idling state based on real world field surveys in Indonesia is very rare. One related research study was done by Nugroho \& Fujiwara (2005), which measured the emission levels in Jakarta city. However, the idle driving condition has still not been estimated in detail. Because of the limited work related to this topic, fieldwork was also conducted to support the actual data available. For this pioneer research, we utilized GPS (Global Positioning System) technology to measure the actual idle driving condition in Jakarta city.

Based on the above problem identification, this research focused on the measurement of idle driving during traffic jam conditions in Jakarta city, calculating the potential avoidable emissions of $\mathrm{CO}$, NO, $\mathrm{HC}$ and the impact of the aforementioned on the emission level of gasoline cars in Jakarta city as a future projection.

Table 1. Data of vehicles in Jakarta

\begin{tabular}{cccccccc}
\hline Year & $\begin{array}{c}\text { Motor } \\
\text { Cycles }\end{array}$ & $\begin{array}{c}\text { Passenger } \\
\text { Cars }\end{array}$ & Cargo Cars & Buses & Special Car & Total & $\begin{array}{c}\text { (irowth for Passenger } \\
\text { Cars (\%) }\end{array}$ \\
\hline 2009 & $7,518,098$ & $2,116,282$ & 550,924 & 309,385 & - & $10,494,689$ & - \\
2010 & $8,764,130$ & $2,334,883$ & 565,727 & 332,779 & - & $11,997,519$ & $10.33 \%$ \\
2011 & $9,861,451$ & $2,541,351$ & 581,290 & 363,710 & - & $13,347,802$ & $8.84 \%$ \\
2012 & $10,825,973$ & $2,742,414$ & 561,918 & 358,895 & 129,113 & $14,618,313$ & $7.91 \%$ \\
2013 & $11,949,280$ & $3,010,403$ & 619,027 & 360,223 & 133,936 & $16,072,869$ & $9.77 \%$ \\
2014 & $13,084,372$ & $3,266,009$ & 673,661 & 362,066 & 137,859 & $17,523,967$ & $8,49 \%$ \\
\hline
\end{tabular}

\section{Materials and Method}

\subsection{Research Framework}

The research framework was constructed by combining the fieldwork with the secondary data from the authorities and the calculation processes. In the first step, the measurement of the traffic density was the focus and became the input used to calculate the time and distance lost during bad traffic conditions. From the time and distance lost, the avoidable emissions were then estimated as described in Fig 1.

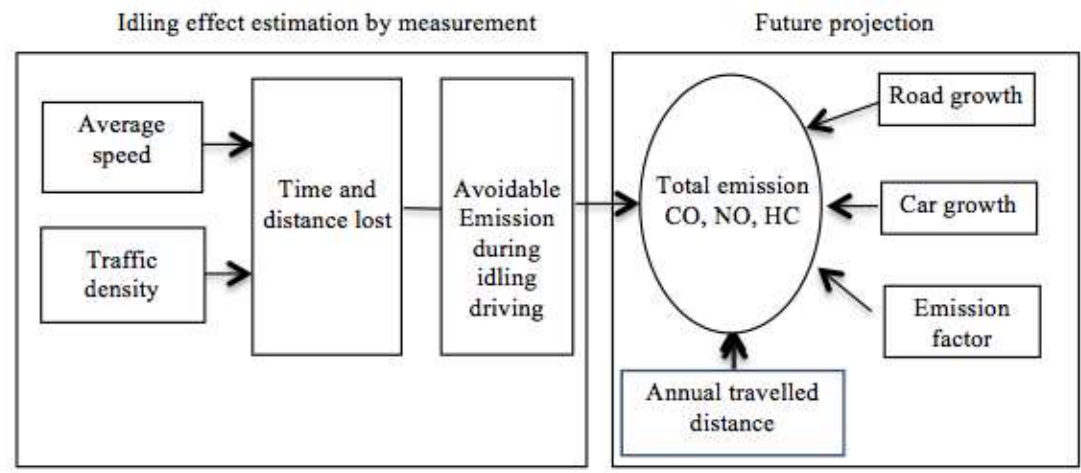

Fig 1. Kesearch tramework

The total emissions were estimated and calculated while accommodating the emission factor and annual travelled distance. To support the calculation of the traffic condition changes, a road growth and car growth comparison was also considered.

\subsection{Traffic density measurement (time and distance lost (or avoided))}

\subsubsection{Sample Selection and Determination}

As we decided to use Jakarta city as the boundary sample area, we used several samples to represent the actual traffic conditions present in the city. The Government Bureau has classified the roads based on their function either as a primary road, secondary road, primary collector or secondary collector as shown in Table 2 (Jakarta, 2014).

Table 2. Road data in Jakarta City (Unit: meter)

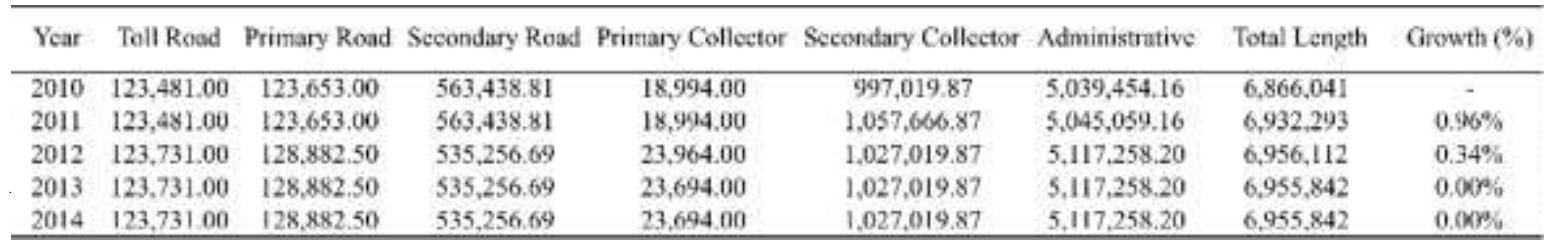


We approached the sample by selecting the most common roads - primary and secondary - to increase the accuracy of the data. For the primary roads, $100 \%$ were measured. However, for secondary roads, in order to simplify the data selection, we set the proportion of the targeted roads at 50\%, 40\%, 30\%, 20\%, and $10 \%$ along with their proportion from the total of the secondary roads in Jakarta city based on the area regency. A map of Jakarta city has been shown in Fig 2 (Geografis Jakarta, 2018).

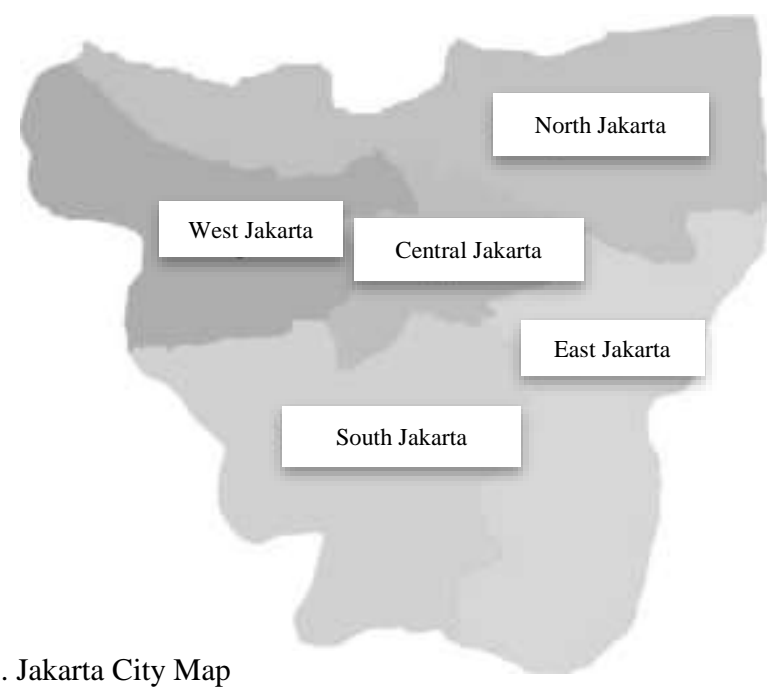

The North Jakarta area has the first rank with the highest road number of 54, resulting in 93,412 kilometers. Central and West Jakarta were placed in second and third rank with the number of roads being $74(89,333$ kilometers) and $68(10,165$ kilometers) respectively. We set the highest proportion as $50 \%$ for North Jakarta, $40 \%$ for Central Jakarta, 30\% for West Jakarta, and the last as $10 \%$ for East Jakarta. The linear proportion was expected to increase the representing level of the data.

One path of the driving sample taken from the selected road will be considered as being 1 sample. The one road path will correspond to the one primary road or secondary road, neglecting the road length variation from each selected road. We also did not consider the driving direction for each path;

both traffic directions will be accepted.

Fig 2. Jakarta City Map

For several roads, the local authority applied either a one-way direction or two-way direction system. On certain paths of road, particular regulations were also applied. For example, since August 2016, the local government has launched new regulations on odd-even car plate numbers to reduce the traffic condition at designated times, particularly in the area surrounding the important public places in the center of Jakarta. However, the number of these roads is low, and thus can be neglected in this experiment.

We also applied the sampling time category for each selected road. We considered that the traffic density of each time slot is potentially different. We created 4 sampling time slots; morning rush hour (06:00-09:00 am), normal weekday (09:00-16:00), evening rush hour (16:00-20:00), and holiday. The morning rush hour is considered to be a peak rush hour time because people are heading in to start work. People drive their car from their home to their office. Some people use public transport such as buses and trains. However, the number of people driving a car for their commute is presumed to still be high. People struggle to reach their office before the average working time, which is generally between 07:00 am and 08:00 am.

On a normal weekday, the traffic condition tends to lower in density. In the evening rush hour, in a general government office, public place, or company, they often end their activities between 16:00-17:00 pm. Therefore the time slot between 16:00-20:00 is considered to be a rush time because people have just finished their work and want to go home. Monday and Friday will be representative of the weekday sampling. We considered that people tend to drive their cars most on these days. This is because both days are connected with a holiday, Saturday and Sunday respectively. People consider driving their car at the end of the weekday (Friday) to directly go to a holiday activity and return on Sunday morning, occasionally going directly to the office. Therefore, Monday and Friday will represent the worst conditions of the weekday traffic.

For holidays, the traffic condition is assumed to differ from the weekday condition. People are not driving outside for work, but they are driving to take a holiday, to go to a public pleasure place, or to visit family and friends. Saturday will be the representative of the holiday sample.

For this sampling category, one road will be driven in the four times slot; morning rush hour, normal weekdays, evening rush hour, and holiday. By considering one path/road's driving as one sample, we measured a total of 1,100 path-roads (1,100 samples taken). We consider these samples to be able to represent the actual traffic conditions of Jakarta city.

\subsubsection{Idle driving time measurement}

Idle driving time is an important element in this experiment. The data will be used to estimate the avoidable emissions produced during the idling condition. We define idle driving as driving at a speed below $5 \mathrm{~km} / \mathrm{h}$ (with $<10 \mathrm{~km} / \mathrm{h}$ as a reference) over a certain distance. We conducted data measurements using a Global Positioning System (GPS) tracker machine that was installed in the vehicle. The Global System for Mobile (GSM) provider sent the recorded data to the server, and an application program (tracksolid) was used to read and extract the data. The Transport Systems Centre (TSC) 
also developed an integrated Global Positioning System (GPS) to measure the traffic condition (Taylor, Woolley \& Zito, 2000).

The procedure involved in the data measurement was as follows:

STEP 1 Prepare all devices installed properly; check that the GPS tracker machine is working properly by checking to see if the indicator lamp is blinking (GPS positioning lamp, data recording lamp). We will also check to see if the GSM data sending method has enough of a data pulse to send the recorded data to the server. The data sending element has been set to record and send the collected data every 10 seconds.

STEP 2 Select the targeted pathway (road) from the city map. The selection of the pathway is determined as shown in Fig. 2.

STEP 3 Start driving. The GPS tracker will record the car speed and positioning data (altitude, longitude), and send it to the server every 10 seconds. The sample data list has been shown in Appendix 1.

STEP 4 To finish the measurement, switching off the GPS tracker will end the process.

In the actual observation procedure, the observed car started from the 0 point assigned as 0 minute before travelling to the determined road with a certain distance. Every 10 seconds, the GPS tracker recorded the speed data and sent it to the server. After this, we extracted all of the data recorded, sent it to the server and exported it into an Excel file format to make it easy to analyze. If the speed was under $20 \mathrm{~km} / \mathrm{h}$, then we defined this as idle driving. Fig 1 is the sample of one path's driving record data after it has been analyzed. The measurement was conducted using one vehicle and the same driver to avoid unexpected external factors occurring from people's driving habits or car specifications, to maintain the consistency of the measurement. Different drivers will cause deviation in the driving habits. The instruments used were the following:
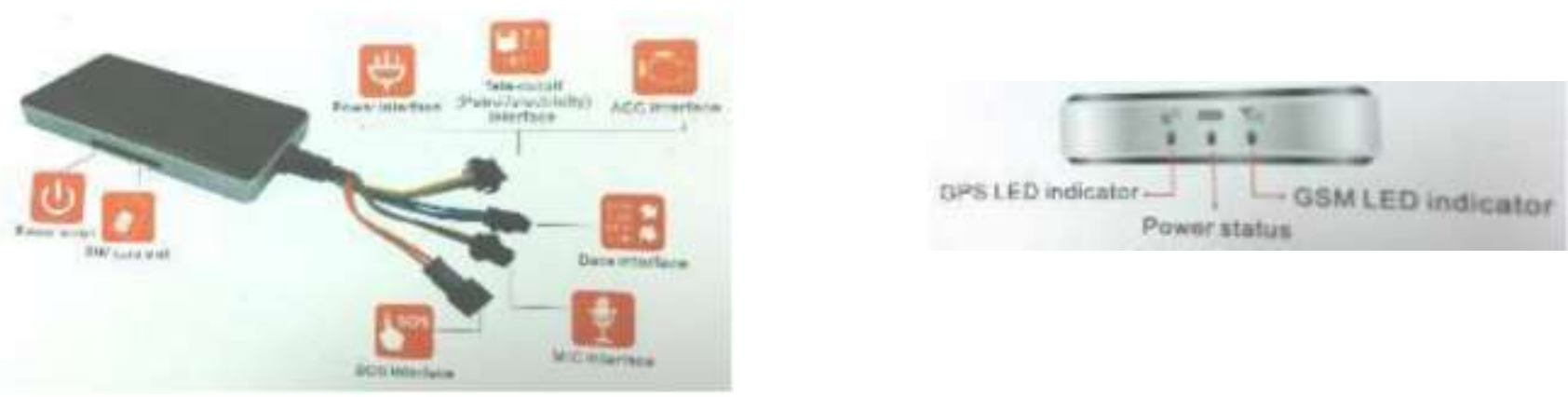

Fig 3. Speed recording instrument

Specifications:
Dimension
Weight
Backup Battery
: $106(\mathrm{~L}) \times 54(\mathrm{~W}) \times 16(\mathrm{H}) \mathrm{mm}$
Operation Temperature
Humidity
$: 96 \mathrm{~g}$
: $450 \mathrm{mAh} / 3.7 \mathrm{~V}$
$:-25^{\circ} \mathrm{C}-60^{\circ} \mathrm{C}$
Standby Time
: $5 \%-95 \%$
GSM Frequencies
GPRS
: 60 hours
: 850/900/1800/1900 MHz
GPS Channel
: Class 12
GPS Sensitivity
$: 20$
Position Accuracy
$:-159 \mathrm{dBm}$
$:-144 \mathrm{dBm}$
TTFF (Open Sky)
GSM GPS Antenna
: $10 \mathrm{~m}$
: Cold Star <38s; Warm Start <15 s; Hot Start <2s
LED Indicator
Data Transmit
: Built-in design
: GSM-green, GPS-blue, Power-red
: TCP, SMS
Geo-fence
: View any existing Geo-fence in the map
Speeding Alarm
: Report when speeds are higher than the pre-set value
Low Power Alarm
: Alarm when the backup battery is running out
Non-Movement Detection : Movement alarm based on built-in 3D motion sensor
Mileage report
: Track by time/distance interval
Remote control
: Cut off petrol/electricity 


\subsubsection{Time lost from idle driving time and determining the average speed}

The idle driving time was derived from the equation of the average speed defined as the distance traveled divided by the total traveled time. Average speed and traveled time were the reverse corresponding factors; when the traveled time was longer, consequently, the average speed was also reduced. On the other hand, the average speed will increase when the traveled time is shorter. A shorter traveled time indicates that the lost time during driving is less. A longer traveled time will show the reverse condition. Shorter traveled time is considered to be the better condition because lost time can be minimized. Time lost was defined using equations (1), (2) and (3), and represents the wasted time while in an idling condition. In idle driving, the car's engine is still in a working condition. However, the car does not travel at the minimum suggested speed.

We defined normal speed as the normal condition that is expected without or with less idle driving time. It has been expressed in the following equation, and $V_{a}$ was calculated from the total traveled distance divided by the total traveled time minus the time spent in a traffic jam that we defined as idle driving time. The total travel distance was calculated from all of the recorded speed range data. The idle driving time was taken from the sum calculation of the speed range under 5 $\mathrm{km} / \mathrm{h}$. For the abnormal conditions that we were not expecting, such as travel in a traffic jam condition, we calculated, from the original condition, the total traveled divided by the total time needed for the travel. Since traffic with an idling time is considered to be an abnormal condition, the actual measured data will be the original condition that represents an abnormal condition. This is because the idling time is still inside the traffic jam.

The definition of a traffic jam is varied depending on the source. From the previous research, the Korean Highway Corporation (KHC) identified traffic congestion spots as being where vehicle speed falls below $30 \mathrm{~km} / \mathrm{h}$ or when the traffic congestion continues for longer than 2 hours a day, 10 days a month. Daejeon city center uses the congestion criteria of when the vehicle speed is less than $14 \mathrm{~km} / \mathrm{h}$. Japan uses speed as a threshold value to identify potential traffic congestion areas. It is said that there is traffic congestion if the freeway travel speed falls below $40 \mathrm{~km} / \mathrm{h}$, if there are repeated 'Stopand-Go's for more than $1 \mathrm{~km}$, or if these conditions stay for more than 15 minutes (Choi et al, 2007).

$$
\begin{aligned}
& T_{\text {lost }}=T_{\text {total }}-T_{\text {idle }} \ldots \ldots \ldots \ldots \ldots \text {....... (1) } \\
& V_{a}=\frac{T D}{T_{\text {lost }}} \ldots \ldots \ldots \ldots \ldots \ldots \ldots \ldots \text { (2) } \\
& V_{b}=\frac{T D}{T_{\text {total }}}
\end{aligned}
$$

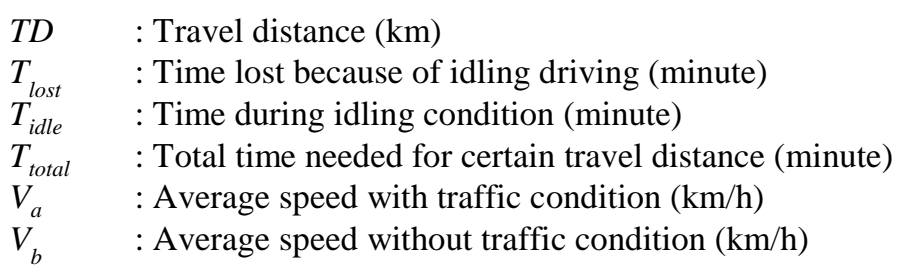

By utilizing the equation above, time lost can be expressed as the difference or gap between time spent in a traffic jam condition and the time without there being a traffic jam condition. The time lost for each sampling path of each road will be summarized in the calculation of the total time lost in Jakarta city. As shown in equation (4), lost travel distance $T D_{\text {lost }}$ is calculated from the average speed with the presence of a traffic jam condition and the time spent in an idling condition. The average speed shows the opposite condition, compared to the time consumed both with traffic and without traffic. Because less idling time will consequently increase the average speed of the traffic, high traffic density with a higher idling condition will cause the average speed to improve. In principle, traffic with a high congestion condition is bad for the environment. This is because cars will continue to emit emission gases even though there is no travel. This condition should be seriously considered and avoided. Unnecessary emission gases should not come from the exhaust pipe while in an idling state. People also do not get any benefits from this condition because they cannot reach their travel target within an effective amount of time. With the expected normal average speed then being resumed, at least some of the travel distance lost can be retrieved.

$$
T D_{\text {lost }}=V_{a} \cdot T_{\text {idle }}
$$


$T D_{\text {lost }}:$ Travel distance lost due to time lost $(\mathrm{km})$

$V_{a} \quad:$ Average speed with traffic condition $(\mathrm{km} / \mathrm{h})$

$T_{\text {idle }} \quad$ : Time during idling condition (minute)

\subsubsection{Avoidable emission estimation}

Idle driving in a high traffic density condition or in a traffic jam causes emissions. Avoidable emissions should not occur, and they can be minimized if the idling time is lessened. Emission gaps with and without idling, $E$, can be calculated from the vehicle data by utilizing the following equation (5). The emissions are the function of travel distance $(T D)$, the emission factor $(E F)$, and the deterioration factor from the catalytic converter $(D F)$. As long as the value of $E F$ and $D F$ are considered to be constant for all conditions and cars, the most influential factor is travel distance. This is because the emission gap is obtained from multiplying the travel distance elements, emission factor, and deterioration factor, in which the distance element value is much higher compared to the other elements. The length of the travel distance in a certain time will produce the difference between the conditions. In the same way of thinking, the amount of emission pollutants in the normal traffic area with and without heavy traffic can be compared.

$$
E_{\text {gap }}=\sum_{N}\left(T D_{a v}-T D_{\text {lost }}\right) \cdot E F \cdot D F
$$

$E_{\text {gap }} \quad$ : Emission gap between with and without lost idling emission (ton)

$T D_{a v} \quad$ : Annual average travel distance $(\mathrm{km})$

$T D_{\text {lost }} \quad$ : Travel distance lost due to time lost $(\mathrm{km})$

EF : Emission factor $(\mathrm{gr} / \mathrm{km})$

DF : Deterioration factor (60\% increase times after 80,000 kilometer travelled; CO $3.52 \mathrm{gr} / \mathrm{km}$; HC $0.08 \mathrm{gr} / \mathrm{km}$; NO $0.72 \mathrm{gr} / \mathrm{km})$

$N \quad$ : Number of recorded traffic condition data

\subsubsection{Future projection}

Emissions in the future were estimated as a future projection by utilizing the driving measurement results. The levels of the avoidable emissions were derived from equations (4) and (5), which were used to determine the emission gap, with the condition of no idle driving being the ideal condition. The time lost during idle driving represents the lost travel distance in equation (1), which was used to calculate and differentiate from the annual travel distance obtained from the survey (Pratama \& Tokai, 2018). Taking into account the detailed driving patterns, including idle driving, increases the accuracy of the travel distance affecting the gas emissions from the vehicles.

Car growth was also used to estimate the number of cars on the road in the future. We estimated the future projection up to 2040 and determined the gas emission tendencies. The contribution of the emissions emitted during idle driving was further analyzed.

\section{Results and Discussions}

\subsection{Target Area}

In this research, we selected Jakarta, the capital city of Indonesia, as the target area. Jakarta can be considered to be representative of the research object because $37 \%$ of the car population is focused in the Jakarta area (Saragih, 2016), with an area of $664.01 \mathrm{~km}^{2}$ and a population of 9,992,842 people in 2017 (Dickson, 2017). On the other hand, Jakarta was named the world's worse city for traffic in one index last year based on satellite navigation data, which found that the average driver started and stopped more than 33,000 times in a year. An estimated 70\% of the city's air pollution comes from vehicles (Mead, 2016).

\subsection{Measurement results of idling time in a traffic jam}

We conducted measurements of selected roads in Jakarta city. We sampled the road traffic condition using a speedrecording instrument as shown in Fig 3. We recorded all of the path road driving speeds to calculate the idling time while travelling on a certain road. 


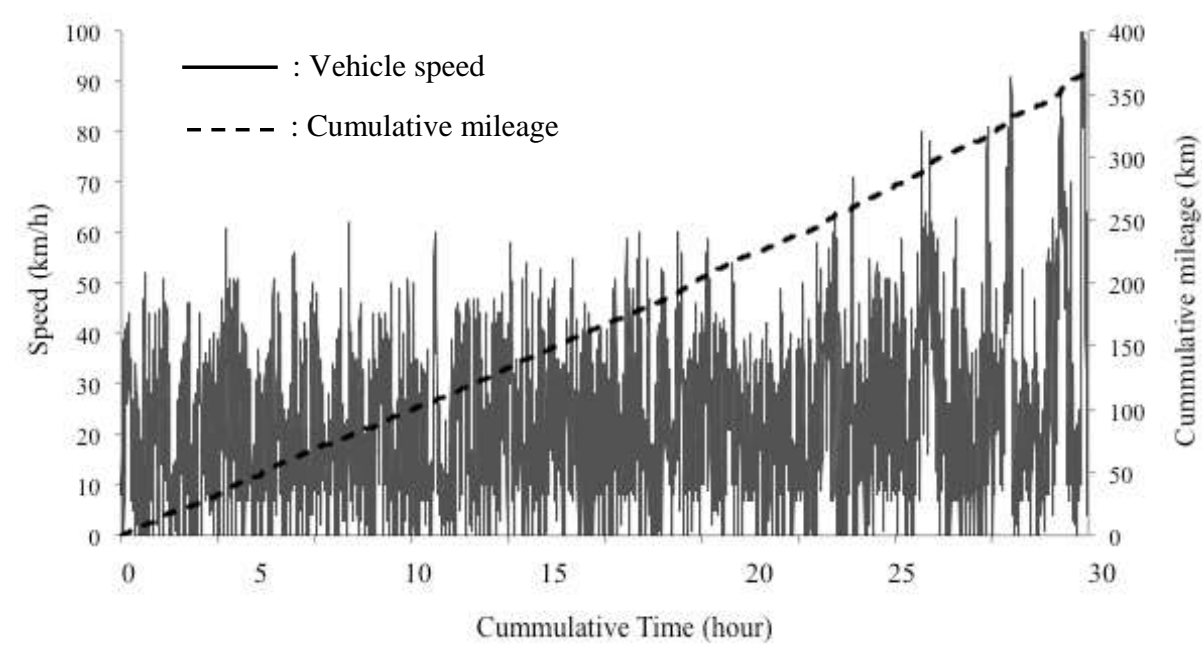

Fig 4. Data measurement result - cumulative time and distance with average speed

We recorded the data as shown in Fig 4, with a total distance of 352 kilometers in the right-Y-axis, and a cumulative driving time of 29.9 hours in the $\mathrm{X}$-axis, taken over a 10 day period. We filtered idling time by selecting when there was a car speed of less than $5 \mathrm{~km} / \mathrm{h}$, while considering that the idle driving fluctuated in the left-Y-axis. By accommodating equations (2), (3) and (4), we calculated the lost travel distance $T D_{\text {lost }}$. Due to the time and financial limitations of this fieldwork, the travel distance was below the targeted $30 \%$ of the total road length. However, as a pioneer research study, we consider this data to be adequate.

From the results, the average speed was $23.9 \mathrm{~km} / \mathrm{h}$ with the distribution for each time sampling shown in Fig 5 (a). The time periods of 06:00-09:00 and 16:00-20:00, described as the rush hours, had an average speed that was lower than the other time periods. The rush hour between 16:00-20:00 had the lowest average speed of $21.6 \mathrm{~km} / \mathrm{h}$ and the time period 06:00-09:00 followed as the next lowest average speed. The highest average speed was $24.7 \mathrm{~km} / \mathrm{h}$. We estimate that the two rush hours contribute more traffic density, causing the average speed to go down compared to the other times.

(a)

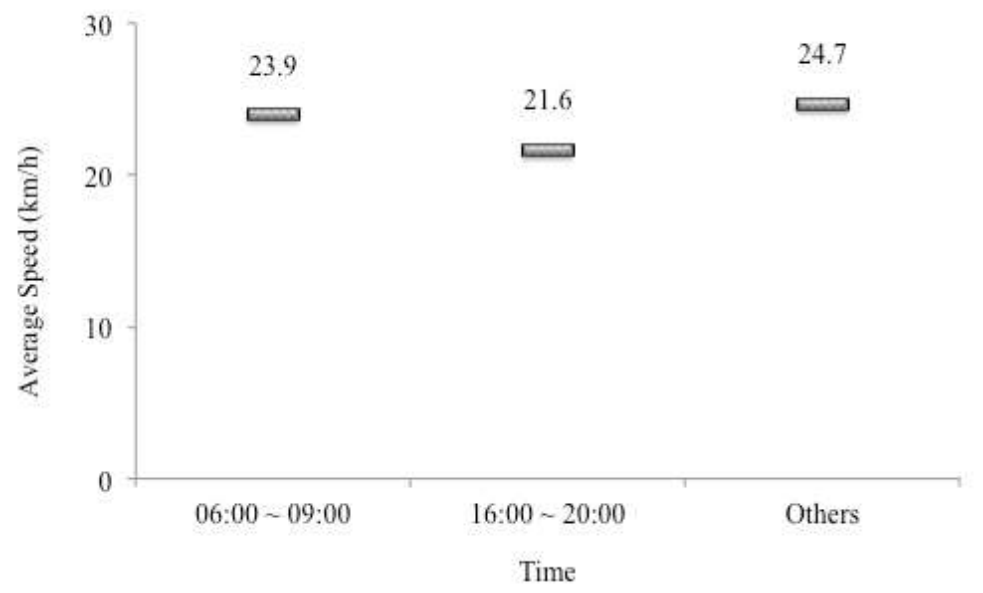


(b)

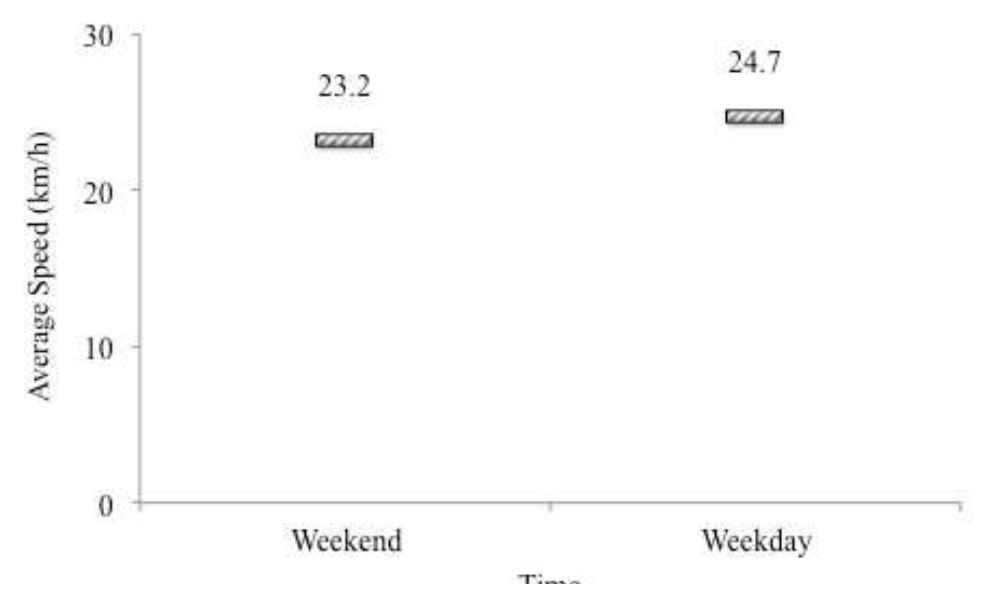

(c)

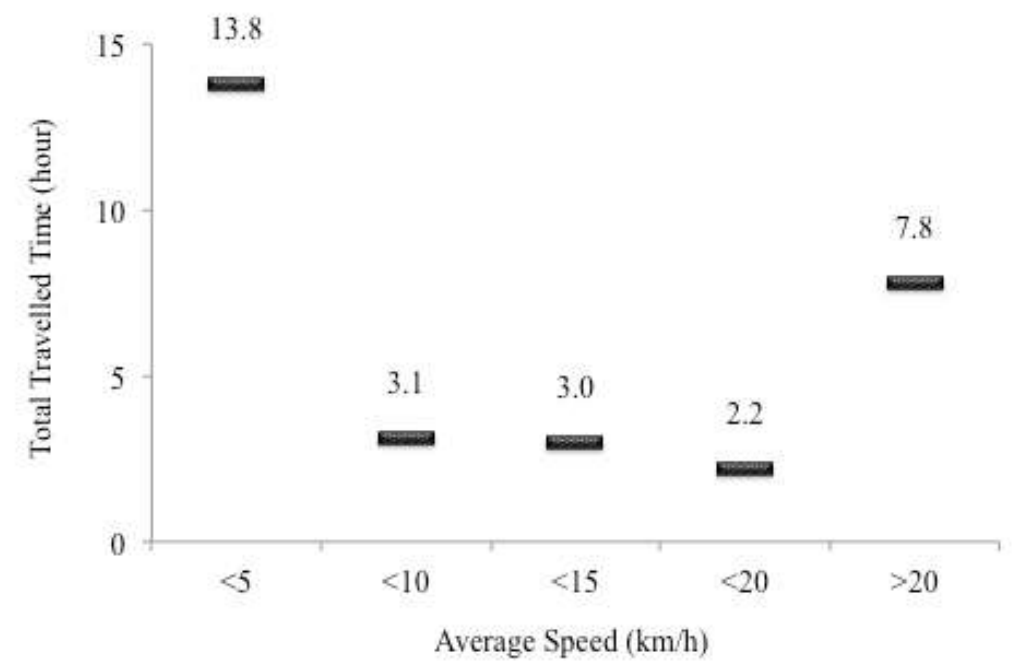

Fig 5 (a) Average speed in the different time periods. (b) Comparison of the average speed between the weekend and weekdays. (c) Total travel time for each average speed segment.

In Fig 5 (b), the weekday time was $6.3 \%$ slower compared to the weekend, with the weekday being $24.7 \mathrm{~km} / \mathrm{h}$ and the weekend being $23.2 \mathrm{~km} / \mathrm{h}$. The weekend was shown to have a better traffic condition compared to the weekdays. We estimate that during the weekend, people travel with their family and use the car for leisure. During the weekdays, they prefer to use public transport due to the time taken and to avoid the time lost due to traffic jam conditions.

The distribution of the average speed has been shown in Fig 5 (c). The segment for the average speed $>5 \mathrm{~km} / \mathrm{h}$ showed the highest total travelled time compared to the others with a total traveled time of 13.8 hours down from the total travel time of 29.9 hours. The average speed $<10 \mathrm{~km} / \mathrm{h}$ was 3.1 hours, with $<15 \mathrm{~km} / \mathrm{h}$ for 3.0 hours, $<20 \mathrm{~km} / \mathrm{h}$ for 2.2 hours and $>20 \mathrm{~km} / \mathrm{h}$ for 7.8 hours. The average speed of $<5 \mathrm{~km} / \mathrm{h}$ dominated the traffic for more than $46 \%$ of the total travelled distance.

\subsection{Emission estimation for the $\mathrm{CO}, \mathrm{HC}, \mathrm{NO}$ gases}

The calculation of the total emissions lost was done by utilizing equation (5) for all vehicles registered in Jakarta city. The gas emissions of CO, NO, and HC have been shown in Fig 6. From Fig 6 (a), the amount of CO in 2020 shows that avoidable emissions during idle driving will reach more than $46.0 \%$ compared to the total emissions without the condition of idle driving. Avoidable emissions in 2020 will be more than double that in 2010 with more than a 41.65 thousand ton increase, which is more than $135.5 \%$. A similar condition also occurs in 2030 , with the emissions up by more than $138.3 \%$, equivalent to 100.08 thousand tons compared to the amount of $\mathrm{CO}$ in 2020 . The end of the projection in 2040 is approximately more than 5.7 times the condition in 2020, with a 338.54 ton difference. Compared with the normal condition that is not $<5 \mathrm{~km} / \mathrm{h}$, idle driving in 2040 produces a 481.79 thousand ton difference, which is more than $46.0 \%$. The condition becomes better if idle driving is expanded to $<10 \mathrm{~km} / \mathrm{h}$. More than $10.0 \%$ of the contribution from the $<10 \mathrm{~km} / \mathrm{h}$ portions will be reduced. 


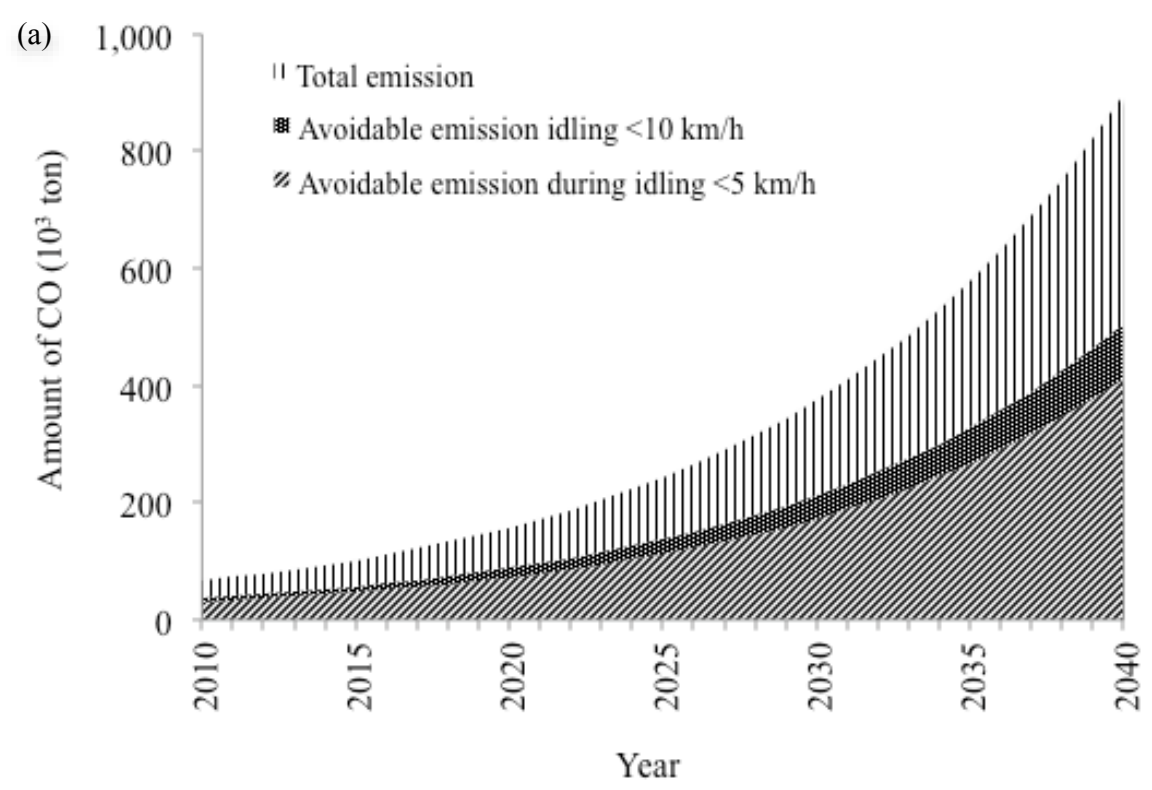

(b)

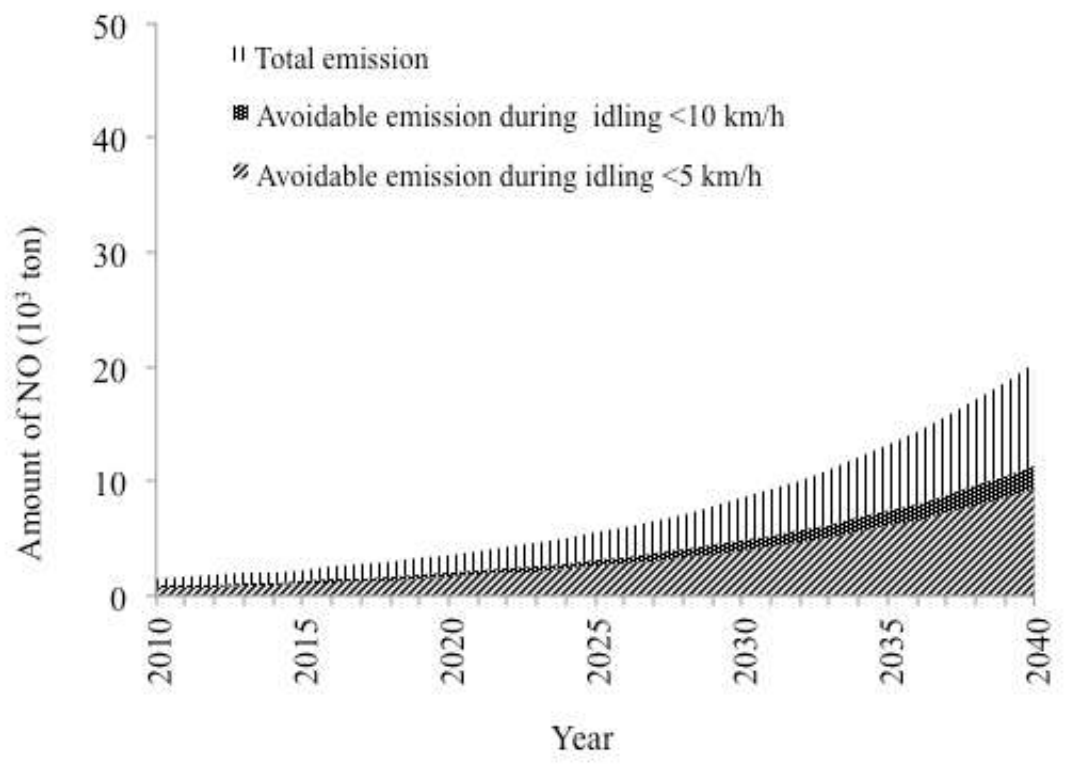

(c)

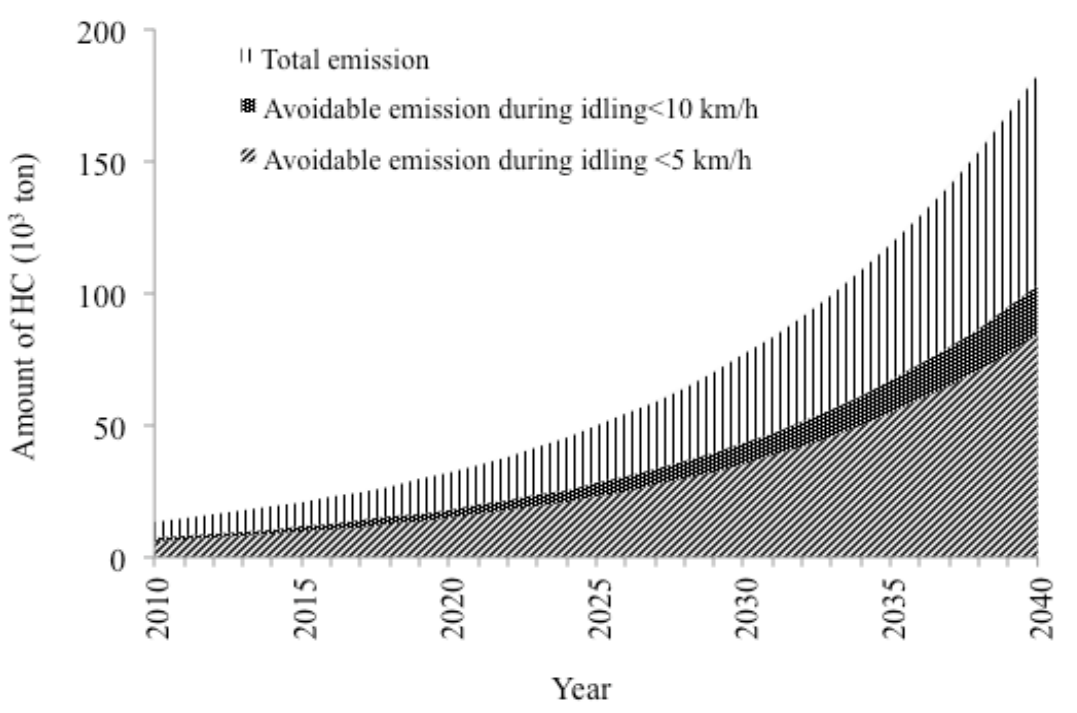

Fig 6. Avoidable emissions of CO (a), NO (b), and HC (c) from the total emissions 
$\mathrm{NO}$ and $\mathrm{HC}$ shows a similar portioning, with more than $46.0 \%$ of the $\mathrm{NO}$ and $\mathrm{HC}$ being released during idle driving in 2020 compared to the normal condition without idle driving. The avoidable emissions of NO and HC in 2030 were $138.3 \%$ compared to those in 2020, with an emission difference of 2,275 thousand tons and 20,472 thousand tons for NO and HC respectively. In 2040, the amount of NO and HC is up by $46.0 \%$ compared to the normal condition in the same year with a total difference of 10,950 thousand tons and 98,549 thousand tons for NO and HC respectively. The percentages of the avoidable emissions ( $\mathrm{CO}, \mathrm{NO}, \mathrm{HC})$ were determined by the percentage portion of the time lost during idle driving from when in the traffic jam condition.

\section{CONCLUSION}

In this paper, we focused on Jakarta city as one of busiest traffic centers in the world. We approached the problem by utilizing GPS technology to measure the actual traffic condition represented by idle driving time and calculated the potential avoidable emissions ( $\mathrm{CO}, \mathrm{NO}, \mathrm{HC})$ and their impact on the emission level of gasoline cars in Jakarta city as a future projection.

Traffic jams in Jakarta city contribute significant and avoidable emission levels. The average speed, by more than $46.0 \%$, was dominated by $<5 \mathrm{~km} / \mathrm{h}$. Expanding the condition of idle driving to $<10 \mathrm{~km}$ will add a contribution of more than $10.0 \%$ to the time and distance lost to idle driving and emissions. In 2040, CO, NO and HC show similar tendencies with an emission difference of more than $46.0 \%$ or 481.79 thousand tons for $\mathrm{CO}, 2,275$ thousand tons for NO, and 20,472 thousand tons for HC. Idle driving contributes a significant amount of emissions when in traffic jam conditions in Jakarta city. Due to the limited sample, increasing the size of the sample will potentially increase the accuracy of the calculation.

We strongly propose reducing these emissions by reducing the idling time. Implementing a technological approach and better idle driving education are two of the options available to solve the problem. The technology option will potentially eliminate emissions, such as implementing an idling stop system. Idle driving education can help drivers to avoid unnecessary emissions. For example, by turning off the engine while in an idle condition or turning off other connected electronic devices on board to reduce the load of the engine. Furthermore, considering more complex factors could increase the benefits of this research, such as the habits of drivers during a traffic jam, diesel engine contribution, or measuring the actual amount of emissions from the exhaust pipe. Improving the average speed is estimated as being able to significantly reduce gas emissions. However, it requires a huge budget and lead-time. Therefore, comprehensive planning and a roadmap become key to these improvements.

\section{ACKNOWLEDGEMENT}

This work was supported by a special project conducted by Tokai laboratory in Osaka University. We would like also to thank The Society for Risk Analysis (SRA) Asia for their support and advice during the International Conference in Taiwan, $21^{\text {st }}-23^{\text {rd }}$ August 2014 and the Risk Governance Symposium, $1^{\text {st }}-2^{\text {nd }}$ September, 2016 in Osaka, Japan. We would also like to say 'thank you' to our colleagues, Dr. Kojima Naoya and Dr. Leticia Sarmento Dos Muchangos, for their fruitful discussion and valuable comments and advice. We thank The Proofers Team Professional Proofreading Services (www.proofers.co.uk) for editing a draft of this manuscript.

\section{REFERENCES}

[1] Badan Pusat Statistik Jakarta. (2015). Transportation statistic of Jakarta. Retrieved from http://jakarta.bps.go.id/backend/pdf_publikasi/Statistik-Transportasi-DKI-Jakarta-2015.pdf

[2] Choi, J., Lee, C., Lee, S., Yu, J. (2007). Development of the Traffic Congestion Index for Freeway Corridors in South Korea.

[3] Dickson. (2017). 10 Kota Terbesar di Indonesia Menurut Jumlah Penduduknya (Ten largest city in Indonesia based on population). Retrieved from http://ilmupengetahuanumum.com/10-kota-terbesar-di-indonesia-menurut-jumlahpenduduknya/

[4] Febri Ardani Saragih. (2016). Ini Jumlah Kendaraan yang Beredar di Jakarta (Number of vehicle in Jakarta). Retrieved from http://otomotif.kompas.com/read/2014/12/11/110000615/Ini.Jumlah.Kendaraan.yang.Beredar.di.Jakarta

[5] Gaines, L., Rask, E., \& Keller, G. (2012). Comparing fuel use and emissions for short passenger car stops, 1-2. Retrieved from http://www.afdc.energy.gov/uploads/publication/which_is_greener.pdf Geografis Jakarta. (2018).

[6] Jakarta, D. B. M. D. P. U. Office of H. (2014). Jumlah jalan Jakarta menurut fungsi (Number of Jakarta Street According to Function). Retrieved from http://www.pu.go.id 
[7] Mead, N. Van. (2016). The world's worst traffic: can Jakarta find an alternative to the car? Retrieved from https://www.theguardian.com/cities/2016/nov/23/world-worst-traffic-jakarta-alternative

[8] Nugroho, S. B., \& Fujiwara, A. (2005). Evaluating the Effects of a New Vehicle Emission Standard on Urban Air Quality in Jakarta City. Journal of International Development and Cooperation, 11(2), 17-37.

[9] Pratama, A., \& Tokai, A. (2018). Passenger Vehicle Emissions in Indonesia: Future Projections. Journal of Sustainable Development, 11 .

[10] Pratama, A., \& Tokai, A. (2018). Study of the incentive caused by the Scrappage program in accelerating old-car replacement in order to reduce gas emissions from gasoline passenger cars in Indonesia. Asian Journal of Applied Sciences, 6(6).

[11] Shancita, I., Masjuki, H. H., Kalam, M. A., Fattah, I. M. R., Rashed, M. M., \& Rashedul, H. K. (2014). A review on idling reduction strategies to improve fuel economy and reduce exhaust emissions of transport vehicles. Energy Conversion and Management, 88, 794-807. http://doi.org/10.1016/j.enconman.2014.09.036

[12] Taylor, M. A. P., Woolley, J. E., \& Zito, R. (2000). Integration of the global positioning system and geographical information systems for traffic congestion studies. Transportation Research Part C: Emerging Technologies, 8(16), 257-285. http://doi.org/10.1016/S0968-090X(00)00015-2 


\section{Appendix 1}

Sample of the recorded raw data.

\begin{tabular}{|c|c|c|c|c|c|c|}
\hline No. & Time & Longitude & Latitude & Speed $(\mathrm{Km} / \mathrm{h})$ & Direction(Degree) & Location Type \\
\hline 1 & $2016-0 \mathrm{~B}-1909: 110 \mathrm{~B}$ & 106.884498 & .6 .139178 & 11 & 14 & satelilite positioning \\
\hline 2 & 2016-08-19 09:11:18 & 106.884347 & -6.138974 & 8 & 348 & satellite positioning \\
\hline 3 & 2016-08-19 09:11:38 & 106.883964 & -6.13888 & 8 & 283 & satellite positioning \\
\hline 4 & $2016-08-1909: 12: 08$ & 106.883716 & -6.138799 & 10 & 289 & satellite positioning \\
\hline 5 & 2016-08-19 09:12:18 & 106.883591 & -6.138703 & 11 & 324 & satellite positioning \\
\hline 6 & $2016-08-19$ 09:12:20 & 106.8836 & -6.138638 & 17 & 3 & satellite positioning \\
\hline 7 & 2016-0B-19 09:12:25 & 106.883671 & -6.132419 & 20 & 18 & satellite positioning \\
\hline 8 & 2016-08-19 09:12:30 & 106.883778 & -6.138095 & 28 & 15 & satellite positioning \\
\hline 9 & 2016-08-19 09:12:35 & 106.883867 & -6.137736 & 31 & 13 & satellite positioning \\
\hline 10 & $2016-08-19$ 09:12:40 & 106.883973 & -6.137298 & 36 & 12 & satellite positioning \\
\hline 11 & 2016-08.19 09:12:45 & 106.884062 & -6.136877 & 31 & 11 & satelfite positioning \\
\hline 12 & 2016-08-19 09:12:50 & 106.884098 & -6.13661 & 13 & 13 & satellite positioning \\
\hline 13 & 2016-08-19 09:12:55 & 106.884204 & -6.136327 & 34 & 15 & satellite positioning \\
\hline 14 & 2016-08-19 09:13:00 & 106.884329 & -6.135848 & 39 & 14 & satellite positioning \\
\hline 15 & 2016-08-19 09:13:05 & 106.884391 & -6.135437 & 29 & 11 & satelfite positioning \\
\hline 16 & 2016-08-19 09:13:15 & 106.884533 & -6.134804 & 15 & 27 & satellite positioning \\
\hline 17 & $2016-0 B-19 \quad 09: 13: 17$ & 106,884578 & -6.134754 & 15 & 65 & satellite positioning \\
\hline 18 & $2016-08-19$ 09:13:20 & 106.884702 & -6.134765 & 22 & 105 & satellite positioning \\
\hline 19 & 2016-08-19 09:13:25 & 106.885058 & -6.134864 & 27 & 105 & satellite positioning \\
\hline 20 & 2016-08-19 09:13:30 & 106.885298 & -6.134945 & 13 & 102 & satellite positioning \\
\hline 21 & $2016-08-19$ 09:13:35 & 106.885547 & -6.135009 & 21 & 106 & satellite positioning \\
\hline 22 & $2016-08-19$ 09:13:40 & 106.885876 & -6.135098 & 26 & 104 & satellite positioning \\
\hline 23 & 2016-0B-19 09:13:45 & 106.886222 & -6.135184 & 26 & 103 & satellite positioning \\
\hline 24 & 2016-08-19 09:13:50 & 106.886542 & -6.135259 & 24 & 103 & satellite positioning \\
\hline 25 & 2016-08-19 09:13:55 & 106.88672 & -6.135307 & 9 & 102 & satellite positioning \\
\hline 26 & 2016-08-19 09:14:03 & 106.886791 & -6.135308 & 0 & 96 & satellite positioning \\
\hline 27 & 2016-08-19 09:14:25 & 106.886773 & -6.135304 & 0 & 96 & satelite positioning \\
\hline 28 & $2016-08-1909: 16: 38$ & 106.886987 & -6.135246 & 0 & 96 & satellite positioning \\
\hline 29 & 2016-08-19 09;16:38 & 106.886987 & -6.135246 & 0 & 96 & satellite positioning \\
\hline 30 & 2016-08-19 09:18:23 & 106.887013 & -6.135501 & 8 & 114 & satellite positioning \\
\hline 31 & 2016-08-19 09:18:28 & 106.887262 & -6.135483 & 10 & 104 & satelfite positioning \\
\hline 32 & $2016-08-1909: 18: 33$ & 106.887547 & -6.135493 & 10 & 103 & satellite positioning \\
\hline 33 & 2016-0B-19 09:18:38 & 106.88768 & -6.135506 & 14 & 104 & satellite positioning \\
\hline 34 & $2016-08-1909: 18: 43$ & 106.887929 & -6.135572 & 23 & 107 & satellite positioning \\
\hline 35 & 2016-08-19 09:18:48 & 106.888258 & -6.135663 & 30 & 106 & satellite positioning \\
\hline 36 & 2016-08-19 09:18:53 & 106.88872 & -6.135764 & 37 & 102 & satellite positioning \\
\hline 37 & $2016-0 \mathrm{~B}-1909: 18: 58$ & 106.8892 & $-6,135875$ & 38 & 103 & satelifte positioning \\
\hline 38 & $2016-08-19$ 09:19:03 & 106.889733 & -6.135986 & 41 & 102 & satellite positioning \\
\hline 39 & 2016-0B-19 09:19:08 & 106.890249 & -6.136108 & 41 & 103 & satellite positioning \\
\hline 40 & $2016-08-19$ 09:19:13 & 106.890702 & -6.136222 & 35 & 104 & satellite positioning \\
\hline 41 & 2016-08-19 09:19:18 & 106.891084 & -6.136341 & 30 & 105 & satellite positioning \\
\hline 42 & 2016-08-19 09:19:23 & 106.891467 & -6.136407 & 30 & 98 & satellite positioning \\
\hline 43 & 2016-0B-19 09:19:28 & 106.891813 & -6.136457 & 20 & 90 & satellite positioning \\
\hline 44 & $2016-08-19$ 09:19:33 & 106.891956 & -6.136397 & 12 & 38 & satellite positioning \\
\hline 45 & 2016-0B-19 09:19:38 & 106,892 & -6.136181 & 23 & 7 & satellite positioning \\
\hline 46 & 2016-08-19 09:19:43 & 106.892036 & -6.135825 & 29 & 7 & satellite positioning \\
\hline 47 & $2016-08-19$ 09:19:48 & 106.892009 & -6.135414 & 32 & 356 & satellite positioning \\
\hline 48 & 2016-08-19 09:19:53 & 106.891964 & -6.134988 & 30 & 352 & satellite positioning \\
\hline 49 & 2016-08-19 09;19;58 & 106.891911 & -6.134589 & 32 & 357 & satellite positioning \\
\hline 50 & 2016-08-19 09:20:03 & 106.89192 & -6.134162 & 34 & 2 & satellite positioning \\
\hline 51 & 2016-08-19 09:20:08 & 106.891964 & -6.133723 & 37 & 7 & satellite positioning \\
\hline 52 & $2016-08-19$ 09:20:13 & 106.892062 & -6.133221 & 41 & 11 & satellite positioning \\
\hline 53 & $2016-08-19$ 09:20:18 & 106.892196 & -6.132772 & 33 & 22 & satellite positioning \\
\hline 54 & $2016-08-19$ 09:20:23 & 106.892356 & -6.132394 & 33 & 23 & satellite positioning \\
\hline 55 & 2016-0B-19 09:20:28 & 106.892578 & -6.131988 & 36 & 28 & satellite positioning \\
\hline 56 & $2016-08-19$ 09:20:33 & 106.892827 & -6.131589 & 38 & 31 & satellite positioning \\
\hline 57 & 2016-08-19 09:20:38 & 106.893093 & $-6.13+119$ & 42 & 25 & satellite positioning \\
\hline 58 & 2016-08-19 09:20:43 & 106.893253 & -6.130619 & 42 & 16 & satellite positioning \\
\hline 59 & 2016-08-19 09:20:48 & 106.893378 & -6.130099 & 42 & 11 & satelite positioning \\
\hline 60 & $2016-08-19$ 09:20:53 & 106.893422 & -6.129609 & 36 & 3 & satellite positioning \\
\hline 61 & 2016-08-19 09:20:58 & 106.893431 & -6.129205 & 29 & 358 & satellite positioning \\
\hline 62 & 2016-08-19 09:21:03 & 106.893413 & -6.128838 & 29 & 356 & satellite positioning \\
\hline 63 & 2016-08-19 09:21:08 & 106.893387 & -6.128433 & 33 & 358 & satellite positioning \\
\hline 64 & 2016-08-19 09:21:13 & 106.893378 & -6.128012 & 32 & 358 & satellite positioning \\
\hline 65 & 2016-0B-19 09:21:18 & 106.893387 & -6.127581 & 36 & 359 & satelite positioning \\
\hline 66 & $2016-08-19$ 09:21:23 & 106.893387 & -6.127125 & 34 & 358 & satellite positioning \\
\hline
\end{tabular}

